\title{
EFEKTIVITAS HEALTH EDUCATION PADA PASIEN DIABETES MELITUS TERHADAP PENCEGAHAN RISIKO INFEKSI PASCA OPERASI KATARAK
}

\author{
Jenny Saherna*1, Dessy Hadrianti², Misdayanti ${ }^{2}$ \\ ${ }^{1,2,3}$ FKIK Universitas Muhammadiyah Banjarmasin \\ e-mail:jenny@umbjm.ac.id
}

\begin{abstract}
Patients after cataract surgery need to know how to properly care for postoperative wounds to minimize the risk of infection. Wound care must be in accordance with aseptik techniques to reduce microorganisms as a factor causing wound infection. Especially in patients with a history of diabetes mellitus, they need knowledge and skills in treating wounds, because they have blood sugar that is prone to increasing over time. This problem is one of the inhibiting factors for the wound healing process. This study used a quantitative method with a pre-experimental design one group pretest - post test using non-probability sampling techniques, purposive sampling method with a sample of 30 respondents. Wilcoxon statistical test was used to analyse the data. The result appeared that it was significant (p), of 0.000 less than $0.05(\alpha)$, namely $(p<\alpha)$. This result means that there is a significant effectiveness between health education in patients with diabetes mellitus in preventing the risk of infection after cataract surgery. Based on these results, nurses need to be aware of the need of health education after cataract surgery, especially to patients with a history of diabetes mellitus. The hospital needs to include this action into the SOP for post-cataract surgery, so that it can be used as an absolute intervention that must be done, so that cooperation is fostered in minimizing the incidence of wound infection, disability and being able to improve the quality of life and reduce patient costs for treatment at the hospital.
\end{abstract}

Keywords: Health education, Infection Risk Prevention, Diabetes Mellitus, Cataract Surgery Wound Treatment.

\begin{abstract}
ABSTRAK
Pasien pasca operasi katarak, perlu tahu bagaimana cara perawatan luka pasca operasi yang benar, agar meminimalisir terjadinya resiko infeksi. Perawatan luka harus sesuai teknik aseptik untuk mengurangi mikroorganisme sebagai salah satu faktor penyebab infeksi luka. Khususnya pada pasien dengan riwayat penyakit diabetes mellitus, mereka membutuhkan pengetahuan dan keterampilan dalam merawat luka, dikarenakan memiliki gula darah yang rentan meningkat disetiap waktunya. Masalah ini menjadi salah satu faktor penghambat proses penyembuhan luka. Penelitian ini mengunakan metode kuantitatif dengan desain pre-eksperimen one group pretest-post test menggunakan nonprobablity sampling metode purposive sampling jumlah sampel 30 responden. Hasil penelitian menggunakan uji statistik Wilcoxon yang menunjukan bahwa signifikan (p), sebesar 0,000 lebih kecil dari $0,05(\alpha)$, yaitu $(\mathrm{p}<\alpha)$, artinya terdapat efektivitas yang signifikan antara health education pada pasien diabetes melitus terhadap pencegahan risiko infeksi pasca operasi katarak. Penelitian ini menunjukkan bahwa perlu adanya kesadaran perawat untuk memberikan health education pasca operasi katarak pada pasien dan terlebih lagi, khususnya kepada pasien dengan riwayat penyakit diabetes melitus. Pihak rumah sakit perlu memasukan tindakan ini kedalam SOP pelayanan pasca operasi katarak agar bisa dijadikan tugas mutlak yang wajib dikerjakan, supaya terbina saling kerjasama dalam meminimalisir kejadian infeksi luka, kecacatan dan mampu meningkatkan kualitas hidup serta mengurangi biaya pasien untuk berobat ke rumah sakit.
\end{abstract}

Kata Kunci: Health education, Pencegahan Risiko Infeksi, Diabetes Melitus, Perawatan Luka Operasi Katarak. 


\section{Pendahuluan}

Penyakit katarak merupakan faktor penyebab dari patalogis proses penyakit yang diderita yaitu individu yang memiliki riwayat penyakit diabetes melitus dan hipertensi, penyebab lainnya disebabkan dari kebiasaan merokok, rata-rata usia penderita yang berisiko mengalami penyakit katarak $\geq 40$ tahun (Harun et al., 2020). Penderita penyakit diabetes melitus tipe 2 , beresiko $40 \%$ mengalami katarak dengan lama menderita diabetes melitus $>10$ tahun dan yang menderita diabetes melitus $\leq 10$ tahun bersiko 60\% mengalami katarak, (Febri Nadyati, Rani Himayani, Giska Tri Putri, 2019).

Jeong \& Lee, (2021) meneliti untuk mengevaluasi tingkat Annual Eye Examination (AEE) dan mengidentifikasi faktor-faktor terkait masalah yang menimpa penderita diabetes melitus. Penelitian ini menunjukkan $12 \%$ laki-laki memiliki potensi untuk mengalami katarak, dengan kriteria inklusi pada mereka yang bukan perokok, memiliki durasi lama menderita diabetes melitus selama 10 tahun, penggunaan insulin dan indeks masa tubuh normal. Sedangkan, pada perempuan secara signifikan sebesar 24,1\% mengalami katarak, khususnya pada mereka yang berusia antara 40-64 tahun dan memiliki durasi lama menderita diabetes melitus selama 10 tahun.

Kebiasaan mengkonsumsi alkohol memiliki tingkat rasio bahaya sebesar 95\% sebagai salah satu penyebab terjadinya katarak dan cenderung operasi katarak, dibandingkan dengan individu yang tidak peminum alkohol akan menjadi lebih rendah 14\% resiko mengalami katarak, (Chua et al., 2021). Seseorang yang melakukan diet vegetarian, lebih banyak mengkonsumsi sayuran yang memiliki asupan seperti kedelai, kacang-kacangan, biji-bijian yang kaya akan vitamin-C, asam folat dan vitamin-A, sehingga akan mendapatkan manfaat yang baik bagi kesehatan tubuh terlebih lagi pada kesehatan mata, menurut (Chiu et al., 2021), dalam penelitiannya yang meneliti kelompok orang dengan kelebihan berat badan, setelah disesuaikan dengan jenis kelamin, pendidikan, kebiasaan merokok, kebiasaan minum alkohol, aktivitas fisik, riwayat hipertensi, diabetes melitus, kortikosteroid dan indeks massa tubuh, didapatkan hasil bahwa seseorang yang diet vegetarian lebih rendah $20 \%$ risiko menderita katarak dibandingkan dengan orang yang memiliki kelebihan berat badan lebih tinggi 95\% mengalami katarak.

Katarak merupakan keadaan ketika lensa mata mengalami kekeruhan, yang menyebabkan penurunan ketajaman penglihatan bahkan kebutaan, apabila seseorang mengalami masalah ini, pengobatannya tidak akan bisa sembuh dengan diberikan obat tetes mata saja, hanya melalui prosedur operasi baru bisa diatasi dan mampu memulihkan ketajaman penglihatan seperti semula. Operasi katarak dengan implant lensa intraocular (IOL) yaitu salah satu yang paling umum dan dianggap sebagai prosedur bedah paling efektif dibidang kedokteran. Walaupun faktor penuaan paling umum penyebab terjadi katarak, tapi ada beberapa faktor lain juga yang bisa menyebabkan katarak seperti patalogis proses penyakit itu sendiri, trauma pada mata, pengaruh efek obat-obatan dan kecenderungan dari penyakit genetik. Memiliki pengetahuan tentang gejala katarak, cara mereka evaluasi dan pemahaman dasar tentang operasi katarak, merupakan bagian integral dalam perawatan primer dari perawatan penyebab utama kebutaan yang harus dicegah secara dini, (Thompson \& Lakhani, 2015).

Tingkat pengetahuan rendah sekitar 53,3\% tentang perawatan pasca operasi katarak dan memiliki sikap negatif $51,1 \%$ tentang perawatan pasca operasi katarak, sebagian besar pasien $51,1 \%$ tidak sesuai melakukan perawatan pasca operasi katarak, menurut (Qurrat \& Silvia, 2018), terdapat hubungan bermakna antara pengetahuan keluarga dengan perawatan pasca operasi katarak dan ada hubungan antara sikap keluarga dengan perawatan pasca operasi katarak.

Health education tentang perawatan luka pasca operasi katarak pada pasien dengan diabetes melitus, perlu diberikan sebelum pasien pulang ke rumah, karena selama mengalami luka, gula darah rentan meningkat sehingga menyebabkan terhambatnya proses penyembuhan luka, mereka tahu bagaimana cara merawat luka matanya setelah operasi, untuk mencegah terjadinya infeksi luka pasca operasi, membantu mempercepat proses penyembuhan luka, selain itu mampu membantu mengurangi biaya perawatan selama masa pemulihan, berdasarkan dari permasalahan tersebut maka peneliti tertarik meneliti tentang "efektivitas health educatin pada pasien diabetes melitus terhadap pencegahan risiko infeksi".

\section{Metode}

Penelitian ini, menggunakan metode kuantitatif dengan desain pre-eksperimen one group pretest-post test menggunakan nonprobablity sampling metode purposive sampling dengan jumlah sampel 30 responden. Teknik pengumpulan data selama 5 hari, dengan memberikan kuesioner pretest dan posttest, yaitu kuesioner dengan 10 pertanyaan tentang pengetahuan katarak dan 10 pertanyaan tentang pengetahuan perawatan luka pasca operasi katarak. Kuesioner sudah dilakukan uji validitas dan uji reabilitas, menggunakan teknik korelasi pearson moment dimana nilai korelasi pada kuesioner ini dinyatakan valid jika $r$ hitung $>r$ tabel. Dengan contoh nilai $r$ tabel dengan 30 responden yaitu. 0.361 . 
Adapun hasil uji validitas pengetahuan tentang katarak $r$ hitung berada antara 0.366-0.705 dan kuesioner tentang pengetahuan perawatan luka pasca operasi katarak $r$ hitung berada antara 0.705-0.366 sehingga kuesioner keduanya dinyakatan valid. Kemudian dilakukan reabilitas dengan uji statistik Cronbach Alpa. Reliabilitas kuesioner dapat diketahui dengan membandingkan dengan $r$ hasil dan nilai $\mathrm{r}$ tabel. Nilai $\mathrm{r}$ hasil adalah alpa. Pernyataan reliabel bila nilai $r$ alpa $>$ nilai $r$ tabel. Nilai reliabilitas yang baik adalah $>0,6$. Adapun hasil uji realibilitas pengetahuan tentang katarak r Alpa berada antara 0.723 dan pengetahuan perawatan luka pasca operasi katarak r alpa berada antara 0.735. kedua kuesioner lebih besar dari 0,6 sehingga dikatakan reabilitas.

Adapun teknik sistematik pelaksanaan kepada responden yaitu dengan cara memberikan persetujuan responden yang sedang menunggu giliran panggil untuk kontrol mata pasca operasi katarak diruang tunggu di puskesmas, menghitung hasil jawaban pengetahuan responden, kemudian memberikan health education tentang bagaiamana cara perawatan luka pasca operasi yang benar untuk mencegah terjadinya infeksi pada luka pasca operasi katarak, setelah itu, memberikan kembali kuesioner post test kepada responden yang sudah diberikan penyuluhan health education.

\section{Hasil Penelitian}

\section{A. Karakteristik Responden}

Tabel 1. Karakteristik responden berdasarkan usia pada pasien pasca operasi katarak.

\begin{tabular}{cccc}
\hline No & Umur & Frekuensi & Persentase \% \\
\hline 1 & $46-55$ & 8 & 26.7 \\
2 & $56-65$ & 15 & 50.0 \\
3 & $65-70$ & 7 & 23.3 \\
\hline & Jumlah & 30 & 100.0 \\
\hline
\end{tabular}

Tabel 1 di atas menunjukkan bahwa karakteristik usia responden pada saat melakukan pengambilan sampel berdasarkan data tertinggi adalah berusia 56-65 tahun yaitu sebanyak 15 responden dengan nilai persentase sebesar $50 \%$.

Tabel 2, karakteristik responden berdasarkan jenis kelamin pada pasien pasca operasi katarak

\begin{tabular}{cccc}
\hline No & Jenis Kelamin & Frekuensi & Persentase \% \\
\hline 1 & Laki-laki & 17 & 56.7 \\
2 & Perempuan & 13 & 43.3 \\
\hline & Jumlah & 30 & 100.0 \\
\hline
\end{tabular}

Tabel 2 di atas menunjukkan bahwa karakteristik jenis kelamin responden pada saat melakukan pengambilan sampel berdasarkan data tertinggi adalah dengan jenis kelamin laki-laki yaitu sebanyak 17 responden dengan nilai persentase sebesar $56.7 \%$.

Tabel 3, karakteristik responden berdasarkan status pernikahan pasien pasca operasi katarak.

\begin{tabular}{clcc}
\hline No & Status pernikahan & Frekuensi & Persentase \% \\
\hline 1 & Menikah & 24 & 80.0 \\
2 & Belum menikah & 1 & 3.3 \\
3 & Duda & 3 & 10.0 \\
4 & Janda & 2 & 6.7 \\
\hline \multicolumn{2}{r}{ Jumlah } & 30 & 100.0 \\
\hline
\end{tabular}

Tabel 3 menunjukkan bahwa karakteristik status pernikahan responden pada saat melakukan pengambilan sampel berdasarkan data tertinggi adalah dengan status menikah yaitu sebanyak 24 responden dengan nilai persentase sebesar $80.0 \%$.

Tabel 4, karekteristik responden berdasarkan tingkat pendidikan pasien pasca operasi katarak.

\begin{tabular}{clcc}
\hline No & Tingkat Pendidikan & Frekuensi & Persentase \% \\
\hline 1 & Tidak sekolah & 8 & 26.7 \\
2 & SD & 13 & 43.3 \\
3 & SMP & 5 & 16.7 \\
4 & SMA & 3 & 10.0 \\
5 & Perguruan tinggi & 1 & 3.3 \\
\hline \multicolumn{2}{c}{ Jumlah } & 30 & 100.0 \\
\hline
\end{tabular}

Tabel 4 menunjukkan bahwa karakteristik pendidikan responden pada saat melakukan pengambilan sampel begbrdasarkan data tertinggi adalah dengan pendidikan SD yaitu sebanyak 13 responden dengan nilai persentase sebesar $43.3 \%$.

Tabel 5, karekteristik responden berdasarkan riwayat penyakit pasien pasca operasi katarak.

\begin{tabular}{clcc}
\hline No & Riwayat penyakit & Frekuensi & Persentase \% \\
\hline 1 & Diabetes Melitus & 14 & 46.7 \\
2 & Jantung & 2 & 6.7 \\
3 & Hipertensi & 10 & 33.3 \\
4 & Hepatitis B & 4 & 13.3 \\
\hline & Jumlah & 30 & 100.0
\end{tabular}

Tabel 5 menunjukkan bahwa karakteristik riwayat penyakit responden pada saat melakukan pengambilan sampel berdasarkan data tertinggi adalah dengan penyakit diabetes melitus yaitu sebanyak 14 responden dengan nilai persentase sebesar $46.7 \%$. 
Tabel 6. Karekteristik responden berdasarkan lama hari pasca operasi katarak pasien pasca operasi katarak.

\begin{tabular}{cccc}
\hline No & $\begin{array}{c}\text { Lama hari pasca } \\
\text { operasi katarak }\end{array}$ & Frekuensi & Persentase \% \\
\hline 1 & Hari Ke 5 & 14 & 46.7 \\
2 & Hari ke 2 & 2 & 6.7 \\
3 & Hari Ke 4 & 10 & 33.3 \\
4 & Hari Ke 3 & 4 & 13.3 \\
\hline & Jumlah & 30 & 100.0 \\
\hline
\end{tabular}

Tabel 6 menunjukkan bahwa karakteristik lama hari pasca operasi katarak responden pada saat melakukan pengambilan sampel berdasarkan data terbanyak adalah pada hari ke 5 pasca operasi katarak, sebanyak 14 responden dengan nilai persentase sebesar $46.7 \%$.

\section{B. Analisis Univariat}

Tabel 8. Pengetahuan responden terhadap pencegahan risiko infeksi pasca operasi katarak sebelum diberikan health education

\begin{tabular}{cccc}
\hline No & $\begin{array}{r}\text { Pengetahuan sebelum } \\
\text { pendidikan kesehatan }\end{array}$ & Frekuensi & Persentase \% \\
\hline 1 & Kurang & 12 & 40.0 \\
2 & Sedang & 9 & 30.0 \\
3 & Baik & 9 & 30.0 \\
\hline & Jumlah & 30 & 100.0 \\
\hline
\end{tabular}

Tabel 8 menunjukkan bahwa tingkat pengetahuan responden terhadap pencegahan resiko infeksi pasca operasi katarak Sebelum diberikan Health education (PreTest) pada saat melakukan pengambilan sampel berdasarkan data terbanyak adalah memiliki tingkat pengetahuan yang kurang yaitu sebanyak 12 responden dengan nilai persentase sebesar $40.0 \%$.

Tabel 9. pengetahuan responden terhadap pencegahan risiko infesksi pasca operasi katarak sesudah diberikan health education

\begin{tabular}{cccc}
\hline No & $\begin{array}{c}\text { Pengetahuan sesudah } \\
\text { pendidikan kesehatan }\end{array}$ & Frekuensi & Persentase \% \\
\hline 1 & Kurang & 3 & 10.0 \\
2 & Sedang & 10 & 33.3 \\
3 & Baik & 17 & 56.7 \\
\hline & Jumlah & 30 & 100.0 \\
\hline
\end{tabular}

Tabel 9 menunjukkan bahwa pengetahuan responden terhadap pencegahan resiko infeksi pasca operasi katarak sesudah (Post test) diberikan health education, pada saat melakukan pengambilan sampel berdasarkan data terbanyak adalah memiliki tingkat pengetahuan yang baik sebanyak 17 responden dengan nilai persentase sebesar $56.7 \%$.

\section{Analisis Bivariat}

Tabel 10. Tabulasi Silang Efektivitas health education Terhadap Pencegahan Resiko Infeksi Pasca Operasi Katarak

\begin{tabular}{|c|c|c|c|c|c|c|c|c|}
\hline \multirow{3}{*}{$\begin{array}{c}\text { Sebelum / Pre } \\
\text { Test }\end{array}$} & \multicolumn{6}{|c|}{ Sesudah / Post Test } & \multirow{2}{*}{\multicolumn{2}{|c|}{ Jumlah }} \\
\hline & \multicolumn{2}{|c|}{ Kurang } & \multicolumn{2}{|c|}{ Sedang } & \multicolumn{2}{|c|}{ Baik } & & \\
\hline & $\mathrm{N}$ & $\%$ & $\mathrm{~N}$ & $\%$ & $\mathrm{~N}$ & $\%$ & $\mathrm{~N}$ & $\%$ \\
\hline Kurang & 3 & 33.3 & 5 & 55.6 & 1 & 11.1 & 9 & 100 \\
\hline Sedang & 0 & 0.0 & 5 & 41.7 & 7 & 58.3 & 9 & 100 \\
\hline Baik & 0 & 0.0 & 0 & 0.0 & 9 & 100 & 12 & 100 \\
\hline Total & 3 & 10.0 & 10 & 33.3 & 17 & 56.7 & 30 & 100 \\
\hline \multicolumn{9}{|c|}{ Uji Normalitas $=\mathbf{0 . 0 0 0}$} \\
\hline \multicolumn{9}{|c|}{ Uji Wilcoxon $=0.000$} \\
\hline
\end{tabular}

Tabel 10 menunjukkan bahwa dari 30 responden, saat pemberian kuesioner di dapatkan bahwa hasil analisis efektivitas Health education terhadap Pencegahan Resiko Infeksi Pasca Operasi Katarak mengalami peningkatan hasil nilai, dari kategori tingkat pengetahuan "kurang" meningkat menjadi kategori pengetahuan "baik", terhadap pengetahuan tentang pencegahan resiko infeksi pasca operasi katarak, sebanyak 17 Responden. Selanjutnya kategori tingkat pengetahuan "kurang" berubah mengalami peningkatan menjadi kategori "sedang" terhadap pengetahuan tentang pencegahan Resiko Infeksi Pasca Operasi Katarak sebanyak 10 Responden.

Hasil uji normalitas menunjukan bahwa distribusi jawaban adalah normal dikarenakan nilai sig < 0.05 yang berfungsi sebagai syarat uji wilcoxon. Hasil uji statistik Wilcoxon menunjukan signifikan yakni sebesar 0,000 yang lebih kecil dari 0,05 sebagai taraf yang telah ditentukan ( $\mathrm{p}<$ $\alpha$ ) dan dapat dinyatakan memiliki efektivitas yang sangat signifikan antara Health education terhadap pencegahan resiko infeksi pasca operasi katarak.

\section{PEMBAHASAN}

Hasil penelitian ini didapatkan berdasarkan data terbanyak pasien yang menderita penyakit katarak rata-rata yaitu, berusia 56-65 tahun. Jenis kelamin terbanyak pada laki-laki, dengan rata-rata status sudah menikah dan berpendidikan lulusan SD (Sekolah Dasar), data tersebut sejalan dengan penelitian (Febri Nadyati, Rani Himayani, Giska Tri Putri, 2019).

Manifestasi klinis dan tanda-tanda gejala keluhan katarak, pada penderita diabetes melitus berisiko 2,32 kali lebih besar rentan mengalami katarak, akibat terjadinya penurunan kemampuan pankreas memproduksi insulin dan berkurangnya kerja insulin memetabolisme makanan yang dikonsumsi, sehingga meningkatkan glukosa dalam darah dan faktor proses 
penuaan (Maryati Tombokan, Sukma saini, Masdiana AR, 2017).

Penyakit diabetes melitus pada penderita katarak, memiliki angka terbanyak sebesar 14 responden dengan nilai persentase sebesar $46.7 \%$ dan hipertensi sebanyak 10 responden sebesar $33.3 \%$, data tersebut menunjukkan bahwa riwayat penyakit penyebab terjadinya katarak berawal dari memiliki kedua keluhan tersebut. Data hasil penelitian ini sejalan dengan penelitian menurut Chiu et al., (2021). Harun et al., (2020) selanjtunya menyampaikan bahwa hipertensi merupakan tanda gejala vital sign terganggung/tidak stabil yaitu terjadi peningkatan tekanan darah diatas normal $\geq 140$ mmhg tekanan siastole, tekanan pada saat jantung distraksi (menarik seluruh darah kedalam jantung) dan tekanan diastole $\geq 100$ mmhg, tekanan pada saat jantung relaksasi (melepaskan darah dari jantung keseluruh tubuh). Hal-hal demikian meningkatkan kekeruhan pada lensa mata sedangkan diabetes melitus merupakan kelainan pankreas yang menyebabkan terganggunya produksi insulin, adanya peningkatan enzim aldose reduktase, sehingga lama-kelamaan mengalami peningkatan enzim, hal ini akan menyebabkan terjadinya kekeruhan pada lensa mata.

Hasil penelitian ini menunjukkanm berdasarkan hari lama pasca operasi katarak yang kontrol ke puskesmas, yaitu pada hari ke 5 pasca operasi katarak, sebanyak 14 responden dengan nilai persentase sebesar 46.7\%. Sitompul (2015) mengatakan bahwa komplikasi dapat dicegah dengan menjalankan prinsip aseptic. Dari sekian banyak pasien yang menjalani operasi katarak, hanya $24 \%$ pasien saja yang menyadari pentingnya kontrol ulang kondisi mata pasca operasi untuk mencegah dini terjadinya komplikasi.

Beyene et al., (2021) dalam penelitiannya, rata-rata kesembuhan luka mata pasca opersi katarak adalah 23 minggu dengan syarat usia pasien antara 16-30 tahun dan 31-45 tahun dan pasein non-diabetes melitus. Namun, pada pasien yang memiliki penyakit diabetes melitus waktu pemulihan menjadi lebih lama dari normalnya. Pasien pasca operasi katarak yang memiliki penyakit diabetes melitus akan mengalami perubahan ketebalan koroid setelah operasi katarak (Torabi et al., 2019).

Komplikasi yang harus diwaspadai pada pasien pasca operasi katarak ialah risiko terjadinya endophtalmitis, merupakan salah satu kegawatdaruratan mata, yang dapat mengakibatkan kebutaan, kejadian ini didapatkan sekitar 0,04 - 4\% dari seluruh tindakan operasi mata pada tahun 2020. Dewanti Widya Astari (2021) menuliskan bahwa sangat dibutuhkan kerjasama semua staf dan pemangku kepentingan, mulai dari fase pre operasi, intra operasi dan post operasi serta lingkungan untuk mencegah komplikasi terjadinya endophtalmitis.

Risiko pencegahan infeksi pasca operasi katarak bisa dilakukan dengan memberikan health education kepada pasien dan keluarganya. Hasil data pada penelitian ini menunjukkan bahwa dari 30 responden, saat pemberian kuesioner didapatkan bahwa hasil analisis efektivitas health education terhadap Pencegahan Resiko Infeksi Pasca Operasi Katarak mengalami peningkatan hasil nilai, dari kategori tingkat pengetahuan "kurang" meningkat menjadi kategori pengetahuan "baik", terhadap pengetahuan tentang pencegahan resiko infeksi pasca operasi katarak, sebanyak 17 Responden. Selanjutnya kategori tingkat pengetahuan "kurang" berubah mengalami peningkatan menjadi kategori "sedang" terhadap pengetahuan tentang pencegahan Resiko Infeksi Pasca Operasi Katarak sebanyak 10 Responden, dapat dinyatakan memiliki efektivitas yang sangat signifikan antara health education terhadap Pencegahan Resiko Infeksi Pasca Operasi Katarak. Hasil tersebut sejalan dengan penelitian menurut Rahani Ayu Amalia, Dwi Utari Widyastuti, (2019) yang menyatakan bahwa hampir setengah pasien dengan post operasi katarak memiliki pengetahuan yang cukup dan memiliki kepatuhan sedang, jadi diharapkan kepada perawat untuk meningkatkan pemberian penyuluhan tentang perawatan post operasi katarak dan klien untuk mencegah terjadinya infeksi luka post operasi katarak

Pasien yang memiliki penyakit diabetes melitus pasca operasi katarak, diwajibkan untuk rutin memeriksakan kadar gula darah minimal 2 hari sekali, karena tubuh yang mengalami luka, sangat rentan memacu peningkatan glukosa darah, oleh sebab itu perlu diberikan dukungan keluarga dengan memberirkan motivasi dalam mengontrol kadar gula darah kepada pasien dengan diabetes melitus pasca operasi katarak, untuk membantu perawtan luka, membantu proses penyembuhan luka dengan deteksi dini penyebab faktor penghambat luka karena peningkatan glukosa darah (Maryati Tombokan, sukma saini, Masdiana AR, 2017). Motivasi dari setiap individu berkaitan dengan pengetahuan yang dimiliki oleh setiap masing-masing individu itu sendiri, sehingga tingkat motivasi pasien yang rendah dipengaruhi oleh pengetahuan yang rendah, terutama tidak didapatkannya health education yang baik, tentang cara pencegahan risiko infeksi pasca operasi katarak. Dian Sukma Dewi Arimbi, Lita (2020) menunjukkan bahwa ada pengaruh antara health education terhadap motivasi pasien diabetes melitus tipe 2 dalam mengontrol kadar gula darah.

Qurrat \& Silvia (2018) dalam hasil penelitiannya menunjukkan bahwa ada hubungan antara 
pengetahuan dan sikap keluarga dengan perawatan pasien post operasi katarak. Sehingga diharapkan kepada pasien dan keluarganya hendaknya mencari tahu informasi tentang bagaimana perawatan yang dilakukan pasca operasi katarak, agar dapat memberikan perawatan yang sesuai kepada pasien, selain mendapatkan health education oleh perawat. Pemberian health education selain dengan penyuluhan bisa juga diberikan dengan metode demonstrasi kepada pasien dan keluarga pasca operasi katarak, perawat memberikan health education dengan menganjurkan kepada pasien dan keluarganya untuk mencoba mempraktikan atau redemonstrasi tentang cara perawatan luka pasca operasi katarak yang benar, sesuai konsep aseptik, sehingga diharapkan pasien dan keluarga mudah mempraktikan di rumah bagaimana cara perawatan yang harus dilakukan. Hal ini mampu meminimalisir terjadinya komplikasi dan infeksi luka serta membantu mengurangi pengeluaran biaya perawatan tambahan akibat kelalaian dan ketidaktahuan dari perawatan luka.

Pada zaman sekarang ini, fasilitas pelayanan kesehatan serba mudah. Selain perawat memberikan health education sebelum pasien pulang ke rumahnya, untuk bisa mengevaluasi atau kontrol perawatan kepatuhan dan disipilin pasien dalam menjalani perawatan luka mata post operasi katarak, bisa dilakukan dari jarak jauh, yaitu melalui via telepon kepada pasien. Perawat bisa memantau apakah pasien sudah sesuai menerapkan obat tetes mata sesuai dosis yang ditetapkan, menggunakan kacamata hitam sebagai pelindung mata dari paparan sinar matahari apabila bepergian keluar rumah, menanyakan kondisi kesehatan pasien perlu tidaknya panggilan dokter dan mengetahui apakah kondisi mata yang dioperasi masalah, keterlambatan penyembuhan luka, pasien sudah benarkah melakukan cara mobilisasi aktivitas selama masa penyembuhan luka dan posisi tidur yang dianjurkan (Gülşen \& Akansel, 2020).

\section{Kesimpulan}

Hasil penelitian ini memiliki efektivitas yang sangat signifikan antara health education terhadap pencegahan resiko infeksi pasca operasi katarak. bahwa dari 30 responden, saat pemberian kuesioner di dapatkan, hasil analisis efektivitas health education terhadap pencegahan resiko infeksi pasca operasi katarak mengalami peningkatan hasil nilai, dari kategori tingkat pengetahuan "kurang" meningkat menjadi kategori pengetahuan "baik", terhadap pengetahuan tentang pencegahan resiko infeksi pasca operasi katarak, sebanyak 17 Responden. Selanjutnya kategori tingkat pengetahuan "kurang" berubah mengalami peningkatan menjadi kategori "sedang" terhadap pengetahuan tentang pencegahan resiko infeksi pasca operasi katarak sebanyak 10 responden.

Health education sangat efektif diberikan kepada pasien pasca operasi katarak, ada berbagai metode yang bisa diberikan oleh perawat yaitu, menggunakan metode penyuluhan, metode demonstrasi dan redemonstrasi dan mengevaluasi lewat via telepon, untuk meningkatkan pengetahuan, sikap keterampilan, motivasi dan mampu mengontorl atau mengevaluasi pasien dari jarak jauh, perihal ini penting dilakukan sebagai perawat demi terciptanya trust saling percaya antara pasien-perawat untuk sama-sama bekerjasama dalam melakukan pencegahan risiko infeksi luka dan menghindari terjadinya komplikasi seperti endophtalmitis sebagai faktor terjadinya kegawatdaruratan mata pasca operasi katarak bahkan mengakibatkan kebutaan yang tidak diinginkan.

\section{Aknowledgement}

Terima kasih kepada Universitas Muhammadiyah Banjarmasin yang sudah memfasilitasi kegiatan penelitian ini sampai akhir.

\section{Daftar Rujukan}

Beyene, A. M., Eshetie, A., Tadesse, Y., \& Getnet, M. G. (2021). Time to recovery from cataract and its predictors among eye cataract patients treated with cataract surgery: A retrospective cohort study in Ethiopia. Annals of Medicine and Surgery, 65(102275), 1-5. https://doi.org/10.1016/j.amsu.2021.102275

Chiu, T. H. T., Chang, C. C., Lin, C. L., \& Lin, M. N. (2021). A Vegetarian Diet Is Associated with a Lower Risk of Cataract, Particularly Among Individuals with Overweight: A Prospective Study. Journal of the Academy of Nutrition and Dietetics, 121(4), 669-677.e1. https://doi.org/10.1016/j.jand.2020.11.003

Chua, S. Y. L., Luben, R. N., Hayat, S., Broadway, D. C., Khaw, K. T., Warwick, A., Britten, A., Day, A. C., Strouthidis, N., Patel, P. J., Khaw, P. T., Foster, P. J., \& Khawaja, A. P. (2021). Alcohol Consumption and Incident Cataract Surgery in Two Large UK Cohorts. Ophthalmology, 128(6), 837-847. https://doi.org/10.1016/j.ophtha.2021.02.007

Dede Achmad Basofi, Wilson, M. A. (2016). Hubungan Jenis Kelamin, Pekerjaan Dan Status Pernikahan Dengan Tingkat Kecemasan Pada Pasien Operasi Katarak Di Rumah Sakit Yarsi Pontianak.

Dewanti Widya Astari, S. R. (2021). STRATEGI 
PENANGANAN

KEPERAWATAN

ASUHAN

ENDOFTALMITIS: A LITERATURE REVIEW. Jurnal Ilmiah Permas, 11(4), 705718.

Dian Sukma Dewi Arimbi, Lita, R. L. I. (2020). Pengaruh Health education terhadap Motivasi Mengontrol Kadar Gula Darah pada Pasien DM Tipe II. Jurnal Keperawatan Abdurrab, 4(1), 66-76.

Febri Nadyati, Rani Himayani, Giska Tri Putri, M. Y. (2019). Hubungan Durasi Menderita Diabetes Melitus Tipe 2 dengan Kejadaian Katarak di RSUD DR.H.Abdul Moeloek Provinsi Lampung. ESSENTIAL:Essence of Scientific Medical Journal, 17(1), 1-4.

Gülşen, M., \& Akansel, N. (2020). Effects of Discharge Education and Telephone Followup on Cataract Patients' Activities According to the Model of Living. Journal of Perianesthesia Nursing, 35(1), 67-74. https://doi.org/10.1016/j.jopan.2019.04.010

Harun, H. M., Abdullah, Z., \& Salmah, U. (2020). Pengaruh Diabetes, Hipertensi, Merokok dengan Kejadian Katarak di Balai Kesehatan Mata Makassar. Jurnal Kesehatan Vokasional, 5(1),

45. https://doi.org/10.22146/jkesvo.52528

Jeong, I. S., \& Lee, E. J. (2021). Current Status and Associated Factors of Annual Eye Examination Among People with Type 2 Diabetes Mellitus: Using the 7th National Health and Nutrition Examination Survey. Asian Nursing Research, 15(4), 239-246. https://doi.org/10.1016/j.anr.2021.07.003

Maryati Tombokan, sukma saini, Masdiana AR, M. R. N. A. (2017). HUBUNGAN DUKUNGAN KELUARGA DENGAN MOTIVASI DALAM MENGONTROL KADAR GULA DARAH PADA PENDERITA DIABETES MELITUS DI WILAYAH KERJA PUSKESMAS PAMPANG KECAMATAN PANAKKUKANG KOTA MAKASSAR. Jurnal Media Keperawatan, 08(02), 39-45.

Qurrat, D., \& Silvia, M. (2018). Hubungan Pengetahuan Dan Sikap Keluarga Dengan Perawatan Post Operasi Katarak Di Poli Mata Rsud Pariaman. Jurnal Kesehatan Medika Saintika, 09(2), 108-113.

Rahani Ayu Amalia, Dwi Utari Widyastuti, P.

\author{
(2019). PENGETAHUAN DAN \\ KEPATUHAN KLIEN TENTANG \\ PERAWATAN POST OPERASI \\ KATARAK. Jurnal Keperawatan, XII(2), \\ 115-120.
}

Sitompul, R. (2015). Perawatan Lensa Kontak untuk Mencegah Komplikasi Ratna Sitompul. EJournal Kedokteran Indonesia, 3(1), 77-85. https://doi.org/10.23886/ejki.3.4811.

Thompson, J., \& Lakhani, N. (2015). Cataracts. Primary Care - Clinics in Office Practice, 42(3), 409-423. https://doi.org/10.1016/j.pop.2015.05.012

Torabi, H., Sadraei, M., Jadidi, K., \& Alishiri, A. A. (2019). Choroidal thickness changes following cataract surgery in patients with type 2 diabetes mellitus. Journal of Current Ophthalmology, 31(1), 49-54. https://doi.org/10.1016/j.joco.2018.07.004 